\title{
Stress Distribution in Human Tibia Bones using Finite Element Analysis
}

\author{
Wanchalerm Tarapoom ${ }^{\mathrm{a}}$ and Tumrong Puttapitukporn ${ }^{\mathrm{b}, *}$ \\ Department of Mechanical Engineering, Faculty of Engineering, Kasetsart University, Bangkok 10900, \\ Thailand

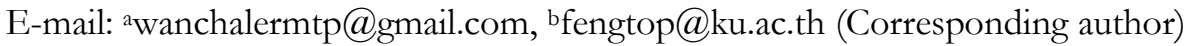

\begin{abstract}
This paper presents the accuracy of finite element models of human tibia bones generated from CT-images used for analyzing stress distribution under loading. The effects of bone structures and material properties (isotropic and orthotropic materials) on stress distribution during stance phrase running were studied. Three-dimensional tibia models were constructed by using Mimics V.10.01, Geomagic V.10 and Catia V.5 software. Then these models were imported into the Hypermesh V.12 software to generate the FE models. Finally the FE models are imported to ANSYS (APDL) V.14.5 software to analysis the stress distribution in the tibia bones. By compared to the benchmark FE model of tibia bones (case studies 13 and 14) resembling to the real bone, we found that there were two sites of maximum von Mises stresses found on tibia bones which were on the middle of posterior tibia and the proximal tibia. However, FE models formed only by cortical bone could not capture the peak stresses on the proximal tibia due to the lack of relatively soft subsurface. The FE models with the medullary cavity formed by cortical bone over predicted the maximum von Mises stress on the middle of posterior tibia while ones with the medullary cavity formed by cancellous bone, bone marrow or bone marrow fat obtained quite similar results. The bone marrow fat in the medullary cavity could not assist to support load on the proximal tibia due to the relatively soft material. The maximum von Mises stresses obtained from FE models with cortical bone formed by orthotropic material were slightly different from ones formed by isotropic material. However, the difference of these FE results was directional cosines that indicated the direction of the crack initiation.
\end{abstract}

Keywords: Tibia bone, finite element, three-dimensional model, CT-images.

ENGINEERING JOURNAL Volume 20 Issue 3

Received 16 September 2015

Accepted 5 January 2016

Published 19 August 2016

Online at http://www.engj.org/

DOI:10.4186/ej.2016.20.3.155 


\section{Introduction}

Many researchers have focused the study on 3D modeling and mechanical properties of human tibia bones. Moreover several computational techniques were proposed on constructing finite element (FE) models of tibia bones for analyzing bone strength under various loading conditions. Tarnita et al. [1] studied CAD method to create the FE models of the tibia bone and also stresses on the tibia bone under various loads. The FE model was obtained from computed tomography (CT) images which consisted of the diaphysis formed by the compact bone having medullary cavity and both epiphyses formed by a cancellous bone covered by a thin layer of compact bone. Sepehri et al. [2] analyzed the effect of mechanical properties on stress induced in tibia. The FEM of the tibia bone had only cortical bone but not spongy bone. Taheri et al. [3] validated mechanical responses between the experiments on the human cadaveric tibia and the FE model based on the same tibia bone consisting of cortical and trabecular bones and anisotropic material properties. Ruchirabha, Puttapitukporn and Sasimontonkul [4] studied stress distribution in the tibia during stance phase running. The FE models of tibia bones consisted of cancellous bone covered by the thin layer of cortical bone. Aroonjarattham and Suvanjumrat [5] studied effect of mechanical axis on strain distribution after total knee replacement. The FE model of tibia bone consisted of the solid diaphysis formed by the compact bone and the distal and proximal ends formed by a spongy bone. Gonzalez-Carbonell et al. [6] studied 3D patient-specific model of the tibia from CT-images used to determine the torque needed to initialize the tibial torsion correction. The FE model of tibia consisted of cortical and trabecular bones and was modeled as an anisotropic material with non-homogeneous mechanical properties.

The objectives of this research are to determine the accuracy of FE models of human tibia bones obtained from CT-images which are commonly found in well-known papers and to determine effects of tibia structure and material properties (isotropic and orthotropic materials) on stress distribution in tibia bones during stance phrase running. The 3D tibia models are constructed by using Mimics V.10.01, Geomagic V.10, and Catia V.5 software. Then these models were imported into the Hypermesh software to generate the FE models. Finally the FE models are imported to ANSYS software to analysis the stress distribution in the tibia bones.

\section{Materials and Methods}

\subsection{Simplified Model}

The simplified tibia model consisting of two concentric cylinders was used to validate accuracy of the ANSYS software as shown in Fig. 1. The outer hollow cylinder has $20 \mathrm{~mm}$ outer radius, $14 \mathrm{~mm}$ inner radius and $350 \mathrm{~mm}$ length. The inner solid cylinder has $4 \mathrm{~mm}$ radius and $350 \mathrm{~mm}$ length. The FE model was formed by 4-node tetrahedral elements having 148,958 elements on the outer cylinder and 118,753 elements on the inner cylinder. The loads were applied to the right end consisting of $5.5 \mathrm{kN}$ compressive force and $0.35 \mathrm{kN}$ shear force. The material properties of outer cylinder were Young's modulus of 14.87 GPa and Poisson's ratio of 0.296 and ones of inner cylinders were Young's modulus of $12 \mathrm{MPa}$ and Possion's ratio of 0.4999 .

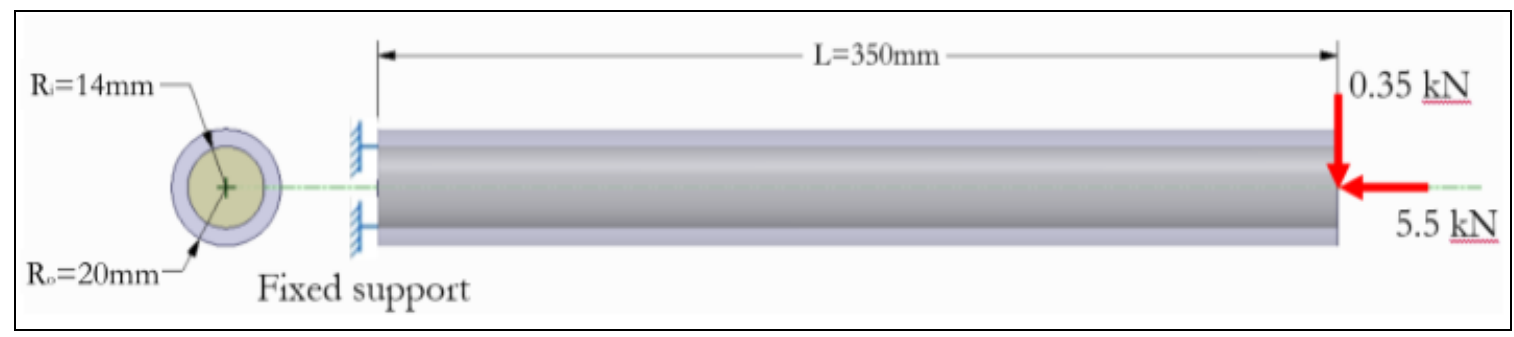

Fig. 1. Simplified model.

\subsection{Tibia Bone Models}

The tibia bone is a long bone which comprises of a diaphysis and two epiphyses on both ends $[8,9,10]$. The diaphysis is the midsection of the tibia bone made of cortical bone and the hollow middle of the bone, 
known as the medullary cavity, is filled with bone marrow. This type of bone marrow is the mostly yellow marrow $[11,12]$ which is mainly made of fat cells $[13,14]$. Both of epiphyses are rounded extremities of the bone and made of cancellous bone.

The CT-images of the lower bodies of 64-year old female and 48-year old male were used to construct the 3D tibia models by using the Mimics V.10.01 software in order to erase irrelevant bones [15] and to create the tibia surfaces as shown in Fig. 2. Then, those tibia surfaces were repaired unsmooth surfaces and created new smoother surfaces using the Geomagic V.10 software. Figure 3 shows the repaired surfaces of the tibia bones of the female and male respectively. After that, the Catia V.5 software was used to form the assembly modeling of diaphysis, two epiphyses and medullary cavity filled with bone marrow as shown in Fig. 4. Finally, those models were exported as IGES files.
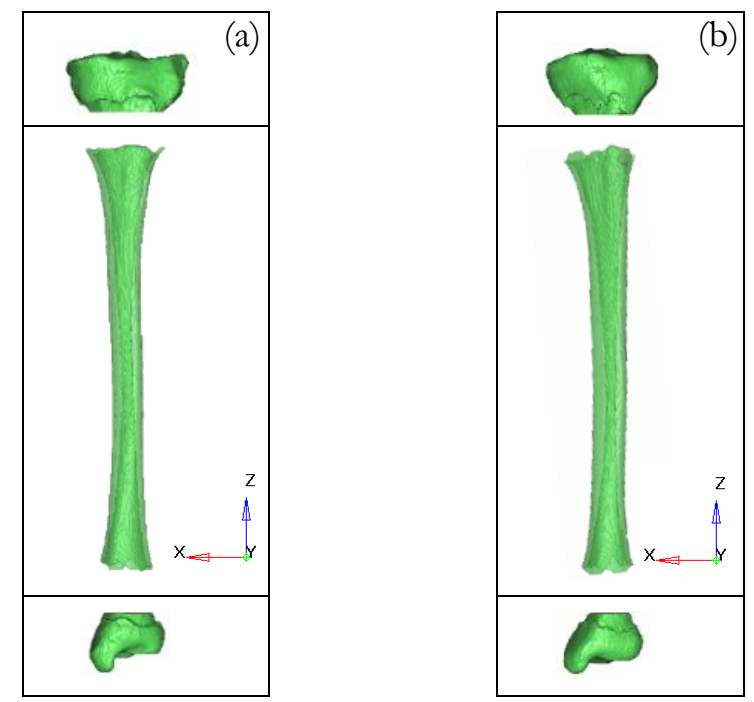

Fig. 2. CT-images of the tibia surfaces consisting of a diaphysis and two epiphyses: (a) female; (b) male.
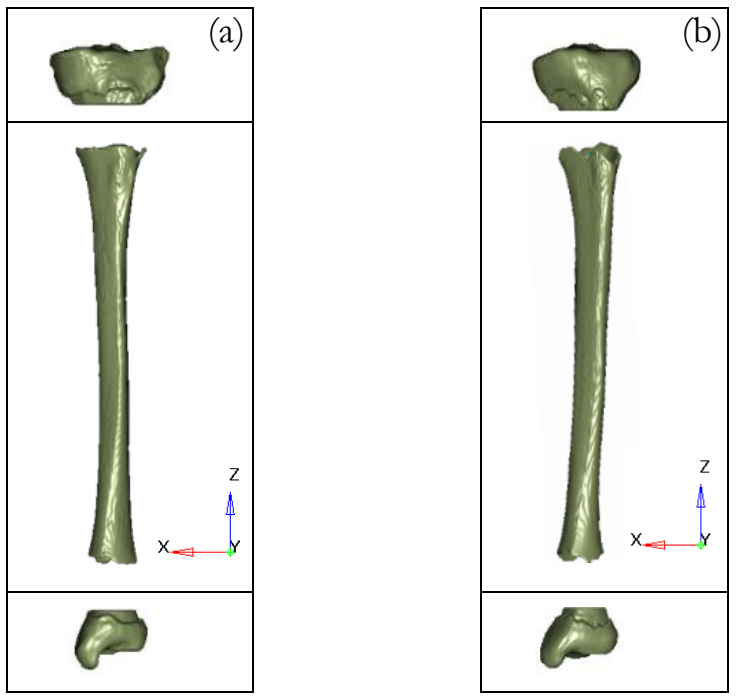

Fig. 3. Repaired tibia surfaces consisting of diaphysis and two epiphyses: (a) female; (b) male. 

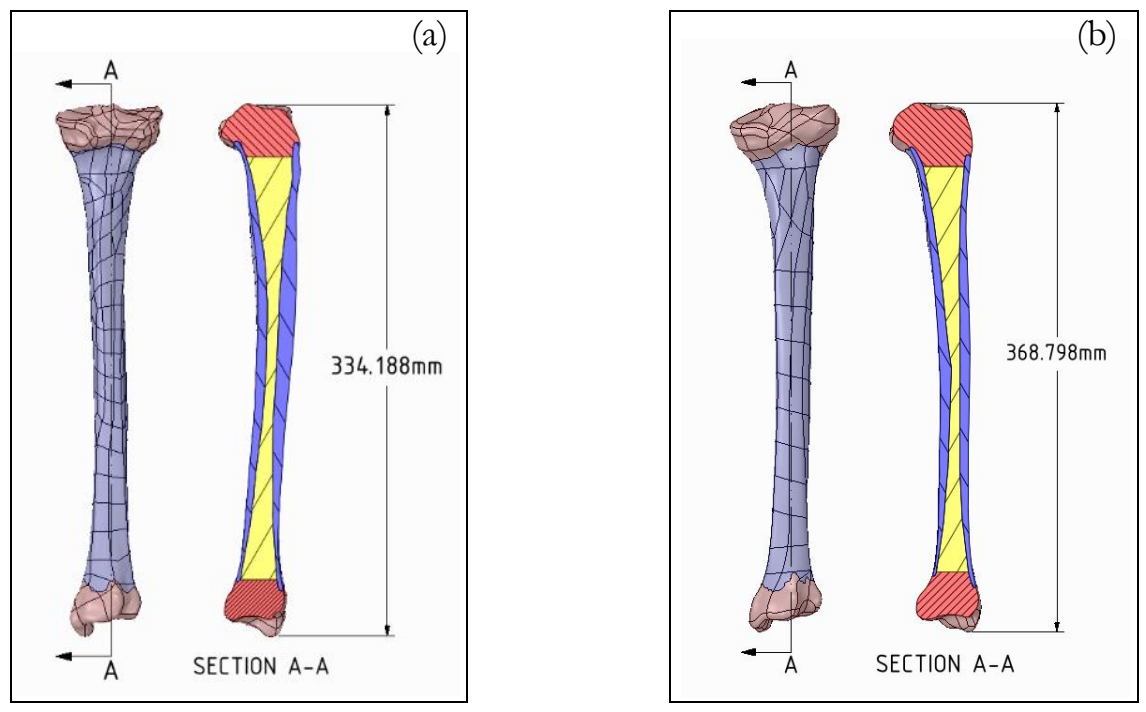

Fig. 4. 3D tibia models consisting of diaphysis, medullary cavity and two epiphyses: (a) female; (b) male.

\subsection{Finite Element Models}

The 3D tibia models were imported into the Hypermesh V.12 software to create FE models. Figure 5 shows the FE models formed by 4-node tetrahedral elements which the numbers of elements is tested to obtain accurate FE results. In this study there were totally fourteen different FE models to evaluate for the effective FE models to use for analyzing stresses in tibia bones during stance phrase running as shown in Table 1. Next, we applied boundary conditions, mechanical properties of tibia bones and loads as shown in Tables 2-4. Finally, the models were exporting into the ANSYS (APDL) V.14.5 software to analyze the FE results.

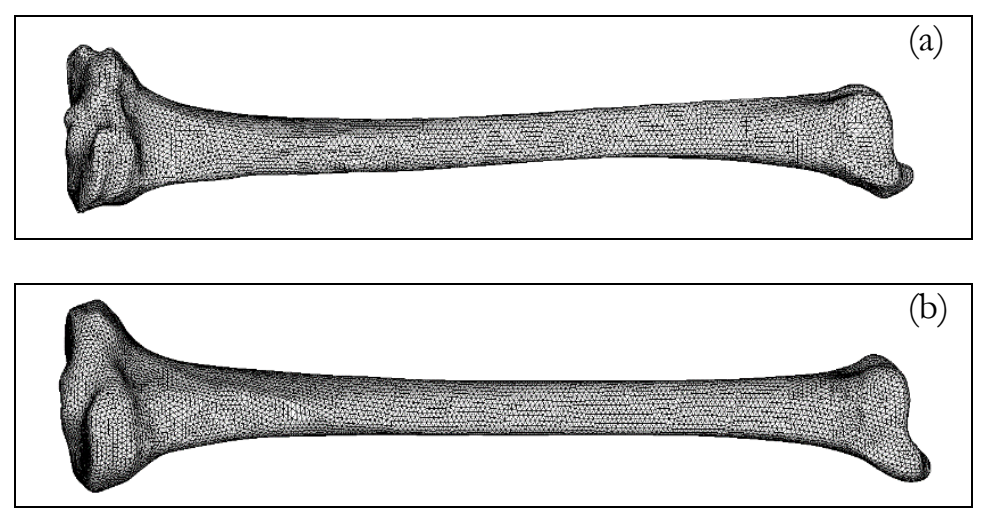

Fig. 5. FE models of tibia bones: (a) female; (b) male.

Table 1. Case studies classified by tibia models and bone materials.

\begin{tabular}{|c|c|c|c|c|c|}
\hline \multirow{2}{*}{$\begin{array}{c}\text { Case study } \\
\text { number }\end{array}$} & \multicolumn{2}{|c|}{ Tibia model } & \multicolumn{3}{|c|}{ Bone material properties } \\
\hline & Female & Male & Two epiphyses & Diaphysis & Medullary cavity \\
\hline 1 & $\sqrt{ }$ & & Cortical bone & Cortical bone & Cortical bone \\
\hline 2 & $\sqrt{ }$ & & Cancellous bone & Cortical bone & Cortical bone \\
\hline 3 & $\sqrt{ }$ & & Cancellous bone & Cortical bone & Cancellous bone \\
\hline
\end{tabular}




\begin{tabular}{|c|c|c|c|c|c|}
\hline 4 & $\sqrt{ }$ & & Cancellous bone & Cortical bone & None \\
\hline 5 & $\sqrt{ }$ & & Cancellous bone & Cortical bone & Bone marrow \\
\hline 6 & $\sqrt{ }$ & & Cancellous bone & Cortical bone & Bone marrow fat \\
\hline 7 & & $\sqrt{ }$ & Cortical bone & Cortical bone & Cortical bone \\
\hline 8 & & $\sqrt{ }$ & Cancellous bone & Cortical bone & Cortical bone \\
\hline 9 & & $\sqrt{ }$ & Cancellous bone & Cortical bone & Cancellous bone \\
\hline 10 & & $\sqrt{ }$ & Cancellous bone & Cortical bone & None \\
\hline 11 & & $\sqrt{ }$ & Cancellous bone & Cortical bone & Bone marrow \\
\hline 12 & & $\sqrt{ }$ & Cancellous bone & Cortical bone & Bone marrow fat \\
\hline 13 & $\sqrt{ }$ & & Cancellous bone & $\begin{array}{c}\text { Cortical bone } \\
\text { (orthotropic material) }\end{array}$ & Bone marrow fat \\
\hline 14 & & $\sqrt{ }$ & Cancellous bone & $\begin{array}{c}\text { Cortical bone } \\
\text { (orthotropic material) }\end{array}$ & Bone marrow fat \\
\hline
\end{tabular}

\subsection{Material Properties}

The isotropic material properties of cortical bone [16], cancellous bone [16], bone marrow [17] and bone marrow fat [18] are provided in Table 2. Table 3 provides the orthotropic material properties of cortical bones obtained from Jae-Young Rho [16].

Table 2. Isotropic material properties of tibia bones for case studies 1-12.

\begin{tabular}{lll}
\hline Type & Young's modulus (GPa) & Poisson ratio \\
\hline Cortical bones & 14.87 & 0.296 \\
Cancellous bones & 0.4 & 0.3 \\
Bone marrow fat & $0.12 \times 10^{-3}$ & 0.499 \\
Bone marrow & 0.3 & 0.45 \\
\hline
\end{tabular}

Table 3. Orthotropic material properties of cortical bones for case studies 13 and 14 .

\begin{tabular}{llll}
\hline Type & Young's modulus (GPa) & Poisson ratio & Shear Modulus (GPa) \\
\hline \multirow{3}{*}{ Cortical bones } & $\mathrm{E}_{1}=11.7$ & $v_{12}=0.42$ & $\mathrm{G}_{12}=4.1$ \\
& $\mathrm{E}_{2}=12.2$ & $v_{23}=0.237$ & $\mathrm{G}_{23}=5.17$ \\
& $\mathrm{E}_{3}=20.7$ & $v_{31}=0.231$ & $\mathrm{G}_{31}=5.7$ \\
\hline
\end{tabular}

\subsection{Boundary Condition}

During stance phrase running, Ruchirabha, Puttapitukporn and Sasimontonkul [4] showed that the FE models of tibia bones with combination of the contact area on the distal end specified by Wan et al. [19] and the contact area on the proximal end at 30 knee flexion specified by Eisenhart-Rothe et al. [20] yielded highest maximum von Mises stress near the middle of the posterior tibia. In this study, the contact areas on the distal end during stance phrase running were modeled according to the study of Wan et al. [19]. Figure 6 illustrates that the contact areas are $224.31 \mathrm{~mm}^{2}(41.07 \%$ of the articular surface) for female and 402.38 $\mathrm{mm}^{2}(41.98 \%$ of the articular surface) for male. Thereafter, compressive and posterior shear forces estimated from average body weights [21] which were $58.58 \mathrm{~kg}$ female and $71.07 \mathrm{~kg}$ male [22] were applied to the FE models are provided in Table 4 . The fixed contact areas on the proximal end of tibia at $30^{\circ} \mathrm{knee}$ flexion were modeled according to the study of Eisenhart-Rothe et al. [20]. Figure 7 shows that these fixed 
contact areas are $81.487 \mathrm{~mm}^{2}$ for female and $76.474 \mathrm{~mm}^{2}$ for male. For both female and male tibia bones, the centroids of the fixed contact areas were $3.2 \mathrm{~mm}$ below the centroid of the medial condyle and $2.2 \mathrm{~mm}$ above the centroid of the lateral condyle.
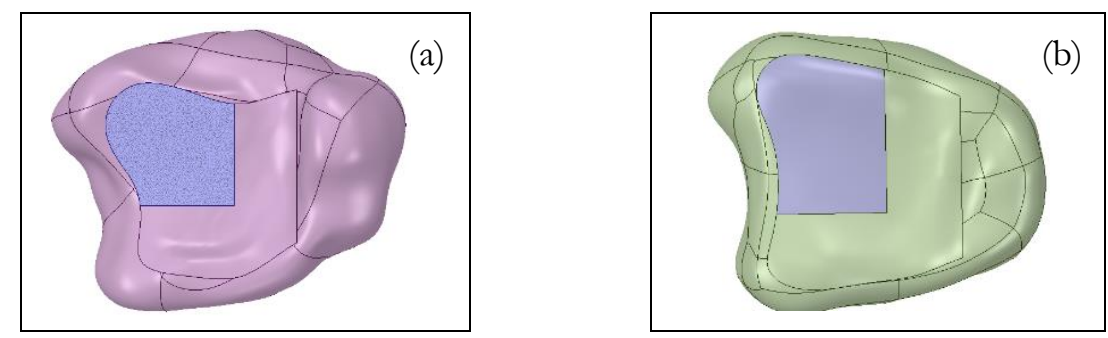

Fig. 6. Contact areas on the distal end of tibias specified by Wan [19]: (a) female; (b) male.

Table 4. Loads applied to contact areas on the distal end of the tibias.

\begin{tabular}{cccc}
\hline Gender & Average body weight (kg) & Compression force (N) & Posterior shear force (N) \\
\hline Female & 58.58 & $5,120.308$ & 304.575 \\
Male & 71.07 & $6,212.023$ & 369.514 \\
\hline
\end{tabular}
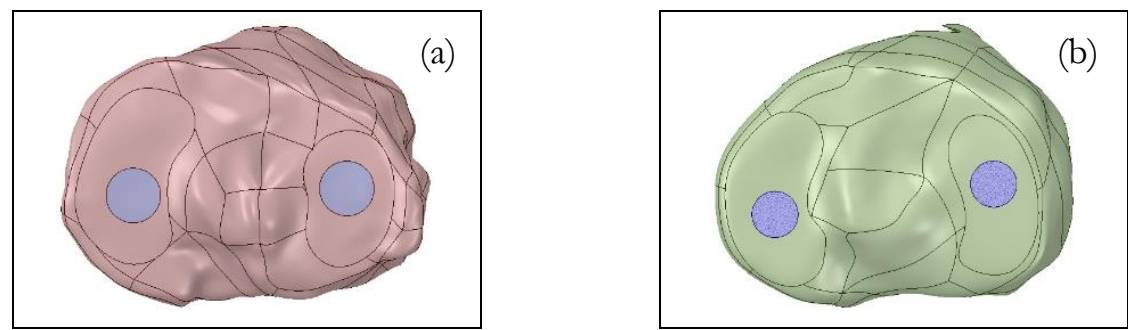

Fig. 7. Fixed contact areas on the proximal end of tibia at $30^{\circ}$ knee flexion: (a) female; (b) male.

\section{Results and Discussion}

In the simplified model, the maximum von Mises stresses obtained from the ANSYS software and analytical solution [7] were 34.262 and $34.239 \mathrm{MPa}$ respectively. This yielded an error less than $0.07 \%$. Figure 8 shows the contour plot of von Mises stress on the simplified model. The volumes of FE models of tibia bones compared to ones of the 3D tibia constructed from the CT-images of case studies 4 and 10 are shown in Fig. 9 and Table 5. To create the effective FE models of tibia bones (of case studies 1 and 7), 4-node linear and 10-node quadratic tetrahedral elements and number of elements were studied to validate accuracy of FE results. Figures 10 and 11 show the plot of maximum von Mises stress versus number of elements comparing the FE models with linear tetrahedral elements to ones with the quadratic tetrahedral elements for female and male tibias respectively. We found the convergence of these FE solutions and percent difference of these FE results was less than $4.5 \%$ when the numbers of elements were greater than 65,000 elements for female tibia and 90,000 elements for male tibia. Since it was too complicated to model the elaborate tibia structure by using the 10-node quadratic tetrahedral elements, in the later study, the tibias were modeled using 4-node linear tetrahedral elements in which the numbers of elements are provided in Table 6.

In the benchmark models (case studies 13 and 14), the FE results showed that there were two sites of maximum von Mises stresses found on tibia bones which were on the middle of posterior tibia and the proximal tibia. Nonetheless, FE models formed by only cortical bone (case studies 1 and 7) could not capture the peak von Mises stresses on the proximal tibia. For case studies 1-6 (female tibia), the maximum von Mises stresses and percentage difference of maximum von Mises stress on the middle of posterior tibia compared to case study 6 (the most intricate structure of female tibia) are shown in Table 7. The maximum von Mises stresses and percentage difference of maximum von Mises stress on the proximal tibia for case 
studies 2-6 compared to case study 6 are shown in Table 8. For case studies 7-12 (male tibia), the maximum von Mises stresses and percentage difference of maximum von Mises stress on the middle of posterior tibia compared to case study 12 (the most intricate structure of male tibia) are shown in Tables 9. The maximum von Mises stresses and percentage difference of maximum von Mises stress on the proximal tibia for case studies 8-12 compared to case study 12 are shown in Table 10. The FE results showed that the FE models with the medullary cavity formed by cortical bone over predicted the maximum von Mises stress on the middle of posterior tibia while ones with the medullary cavity formed by cancellous bone, bone marrow or bone marrow fat obtained quite similar results. The FE results comparing case study 4 to case study 6 and case study 9 to case study 12 showed that bone marrow fat in the medullary cavity could not assist to support load on the proximal tibia. The principle stresses and direction cosines of the principle stress $\sigma_{3}$ at the site of maximum von Mises stress for case studies 1-12 on the middle of posterior tibia and the proximal tibia are shown in Tables 11 and 12, respectively. The maximum von Mises stresses, principal stresses and direction cosine of $\sigma_{3}$ at site of maximum von Mises stresses for case studies 13 and 14 on the middle of posterior tibia and the proximal tibia are shown in Tables 13 and 14, respectively. Figure 12 shows the von Mises stress distributions on the tibia surfaces for case studies 1-12. Figure 13 shows the von Mises stress distributions on the tibia surfaces for case studies 13 and 14. The maximum von Mises stresses obtained from FE models with cortical bone formed by orthotropic material were slightly different from ones formed by isotropic material for both female and male tibias. However, the major difference of these FE results was directional cosines that indicated the direction of the crack initiation.

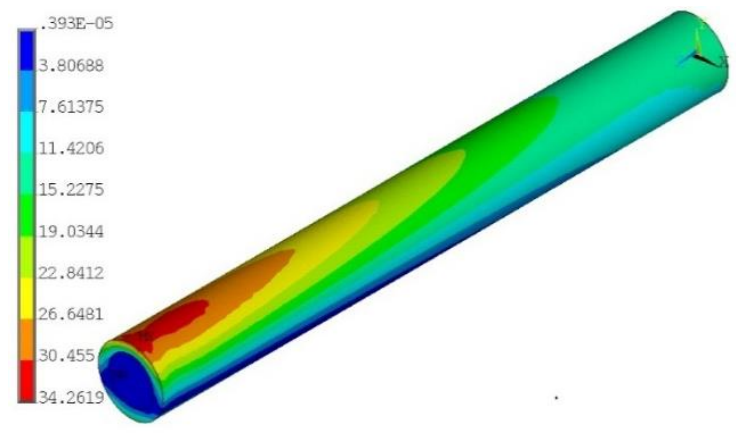

Fig. 8. Contour plot of the von Mises stress distribution (MPa) in the simplified model.
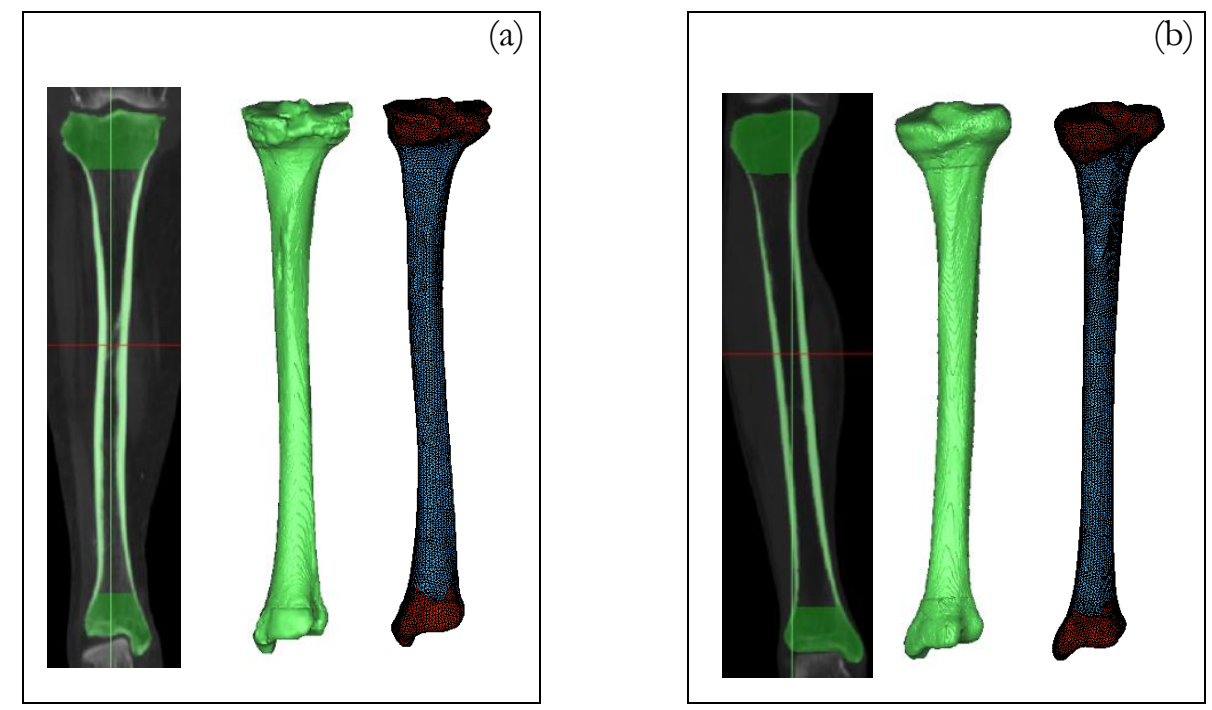

Fig. 9. The cross section of 3D tibia (left), 3D tibia (middle) and FE models (right): (a) female (case study 4); (b) male (case study 10). 
Table 5. Comparison of accuracy of FE tibia models to 3D tibia with the medullary cavity (case studies 4 and 10).

\begin{tabular}{cccc}
\hline \multirow{2}{*}{ Gender } & \multicolumn{2}{c}{ Volume $\left(\mathrm{mm}^{3}\right)$} & $\begin{array}{c}\text { Percent difference } \\
\text { of volume }\end{array}$ \\
\cline { 2 - 3 } & CT-images & FEM & $2.73 \%$ \\
Female & $161,502.63$ & $157,149.23$ & $0.31 \%$ \\
Male & $231,168.37$ & $230,459.11$ & \\
\hline
\end{tabular}

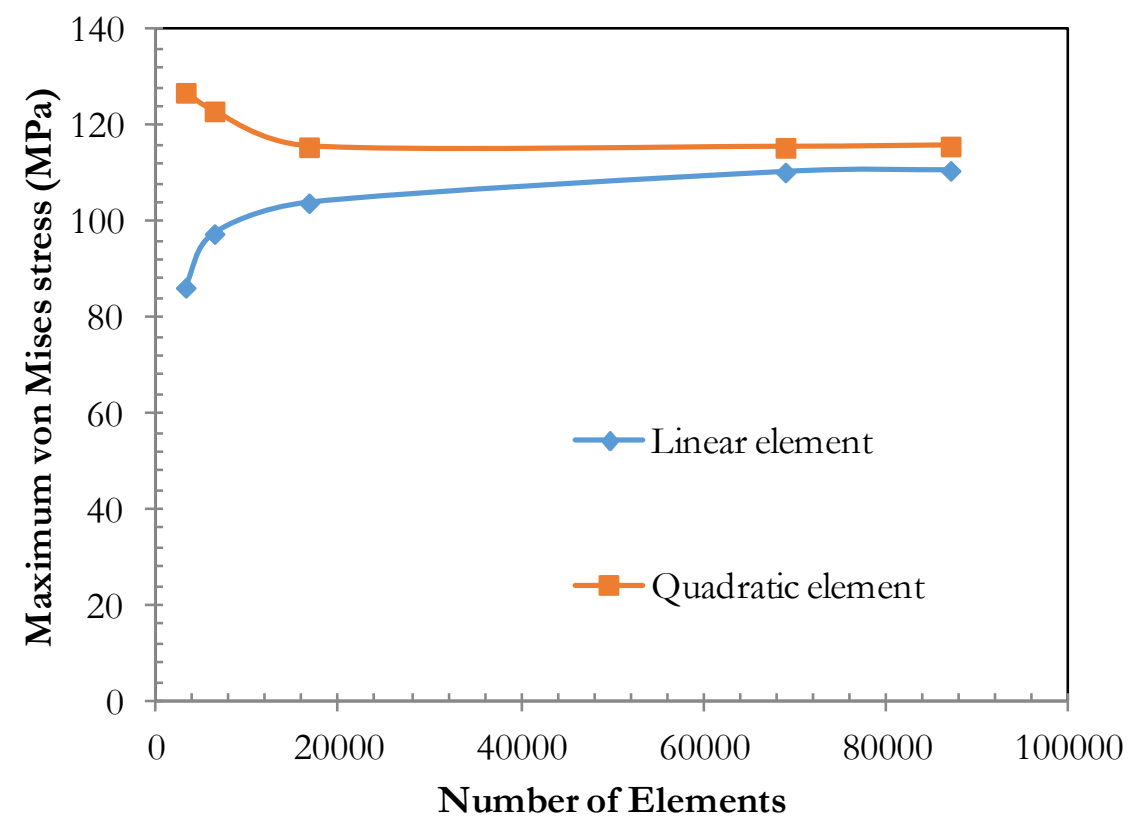

Fig. 10. Number of elements versus the maximum von Mises stress near the middle of the posterior tibia for linear and quadratic elements of female tibia (case studies 1).

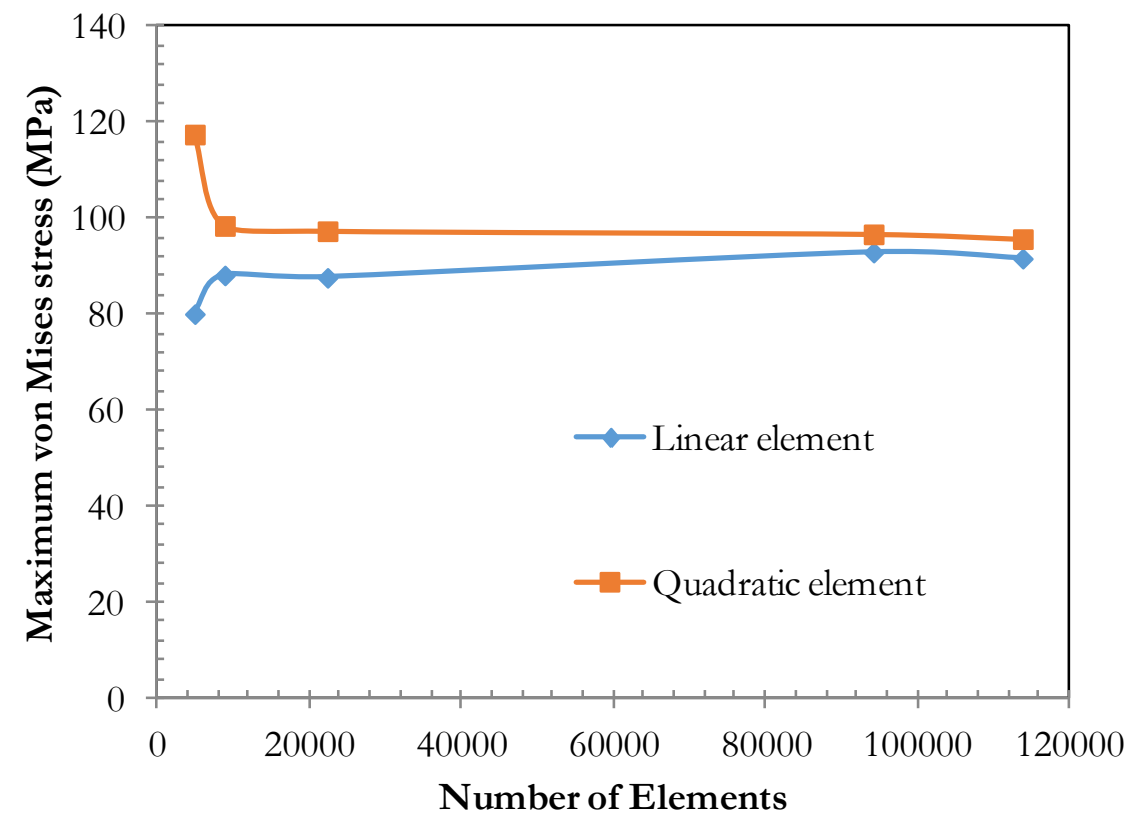

Fig. 11. Number of elements versus the maximum von Mises stress near the middle of the posterior tibia for linear and quadratic elements of male tibia (case studies 7). 
Table 6. Number of nodes and elements used in FE models.

\begin{tabular}{lll}
\hline Case study number & Number of nodes & Number of elements \\
\hline $1,2,3,5,6,13$ & 20,005 & 68,929 \\
4 & 16,678 & 67,120 \\
$7,8,9,11,12,14$ & 25,631 & 94,177 \\
10 & 21,938 & 92,017 \\
\hline
\end{tabular}

Table 7. Maximum von Mises stresses near the middle of the posterior tibia and the percentage difference of maximum von Mises stress compared to case study 6 for case studies 1-6.

\begin{tabular}{ccc}
\hline $\begin{array}{c}\text { Case study } \\
\text { Number }\end{array}$ & $\begin{array}{c}\text { Maximum von Mises stresses } \\
(\mathrm{MPa})\end{array}$ & $\begin{array}{c}\text { \% Difference of maximum von Mises } \\
\text { stress compared to case study 6 }\end{array}$ \\
\hline 1 & 110.15 & 6.98 \\
2 & 110.15 & 6.98 \\
3 & 117.877 & 0.2 \\
4 & 118.119 & 0 \\
5 & 117.918 & 0.17 \\
6 & 118.118 & 0 \\
\hline
\end{tabular}

Table 8. Maximum von Mises stresses on the proximal tibia and the percentage difference of maximum von Mises stress compared to case study 6 for case studies 2-6.

\begin{tabular}{ccc}
\hline $\begin{array}{c}\text { Case study } \\
\text { Number }\end{array}$ & $\begin{array}{c}\text { Maximum von Mises stresses } \\
(\mathrm{MPa})\end{array}$ & $\begin{array}{c}\text { \% Difference of maximum von Mises } \\
\text { stress compared to case study 6 }\end{array}$ \\
\hline 2 & 118.952 & 6.37 \\
3 & 115.585 & 9.24 \\
4 & 126.96 & 0.14 \\
5 & 114.579 & 10.11 \\
6 & 126.781 & 0 \\
\hline
\end{tabular}

Table 9. Maximum von Mises stresses near the middle of the posterior tibia and the percentage difference of maximum von Mises stress compared to case study 12 for case studies 7-12.

\begin{tabular}{ccc}
\hline $\begin{array}{c}\text { Case study } \\
\text { Number }\end{array}$ & $\begin{array}{c}\text { Maximum von Mises stresses } \\
(\mathrm{MPa})\end{array}$ & $\begin{array}{c}\text { \% Difference of maximum von Mises } \\
\text { stress compared to case study 12 }\end{array}$ \\
\hline 7 & 92.979 & 7.04 \\
8 & 92.979 & 7.04 \\
9 & 99.545 & 0.22 \\
10 & 99.769 & 0 \\
11 & 99.562 & 0.21 \\
12 & 99.767 & 0 \\
\hline
\end{tabular}

Table 10. Maximum von Mises stresses on the proximal tibia and the percentage difference of maximum von Mises stress compared to case study 12 for case studies 8-12.

\begin{tabular}{ccc}
\hline $\begin{array}{c}\text { Case study } \\
\text { Number }\end{array}$ & $\begin{array}{c}\text { Maximum von Mises stresses } \\
(\mathrm{MPa})\end{array}$ & $\begin{array}{c}\text { \% Difference of maximum von Mises } \\
\text { stress compared to case study 12 }\end{array}$ \\
\hline 8 & 118.834 & 1.05 \\
9 & 119.532 & 0.46 \\
10 & 120.095 & 0 \\
11 & 119.625 & 0.39 \\
12 & 120.089 & 0 \\
\hline
\end{tabular}


Table 11. Principle stresses and direction cosine of $\sigma_{3}$ at the site of maximum von Mises stresses near the middle of the posterior tibia for case study 1-12.

\begin{tabular}{ccccccc}
\hline \multirow{2}{*}{$\begin{array}{c}\text { Case study } \\
\text { number }\end{array}$} & \multicolumn{3}{c}{ Principle stresses $(\mathrm{MPa})$} & \multicolumn{3}{c}{ Direction cosine of $\sigma_{3}$} \\
\cline { 2 - 7 } & $\sigma_{1}$ & $\sigma_{2}$ & $\sigma_{3}$ & $\lambda_{1}$ & $\lambda_{2}$ & $\lambda_{3}$ \\
\hline 1 & -0.494 & -2.793 & -111.78 & 0.0315 & 0.0385 & 0.9988 \\
2 & -0.494 & -2.793 & -111.78 & 0.0315 & 0.0385 & 0.9988 \\
3 & -0.451 & -3.355 & -119.75 & 0.0322 & 0.038 & 0.9988 \\
4 & -0.443 & -3.424 & -120.02 & 0.0323 & 0.038 & 0.9988 \\
5 & -0.467 & -3.146 & -119.7 & 0.0322 & 0.038 & 0.9988 \\
6 & -0.443 & -3.415 & -120.02 & 0.0323 & 0.038 & 0.9988 \\
7 & -3.066 & -3.918 & -96.469 & -0.0093 & -0.0082 & 0.9999 \\
8 & -3.066 & -3.918 & -96.469 & -0.0093 & -0.0082 & 0.9999 \\
9 & -0.885 & -2.148 & -101.06 & 0 & 0.0246 & 0.9997 \\
10 & -0.895 & -2.188 & -101.3 & 0.0001 & 0.0247 & 0.9997 \\
11 & -0.882 & -2.114 & -101.05 & -0.0001 & 0.0246 & 0.9997 \\
12 & -0.894 & -2.186 & -101.3 & 0.0001 & 0.0247 & 0.9997 \\
\hline
\end{tabular}

Table 12. Principle stresses and direction cosine of $\sigma_{3}$ at the site of maximum von Mises stresses on the proximal tibia for case study 1-12.

\begin{tabular}{ccccccc}
\hline \multirow{2}{*}{$\begin{array}{c}\text { Case study } \\
\text { number }\end{array}$} & \multicolumn{3}{c}{ Principle stresses $(\mathrm{MPa})$} & \multicolumn{3}{c}{ Direction cosine of $\sigma_{3}$} \\
\cline { 2 - 7 } & $\sigma_{1}$ & $\sigma_{2}$ & $\sigma_{3}$ & $\lambda_{1}$ & $\lambda_{2}$ & $\lambda_{3}$ \\
\hline 1 & -0.4941 & -2.7928 & -111.78 & 0.0315 & 0.0385 & 0.9988 \\
2 & -7.2322 & -27.591 & -135.05 & 0.0639 & 0.6048 & 0.7938 \\
3 & 2.7288 & -21.162 & -122.93 & 0.0672 & 0.4221 & 0.9041 \\
4 & 5.3774 & -24.757 & -133.94 & 0.0671 & 0.4149 & 0.9074 \\
5 & 2.5836 & -18.438 & -121.05 & 0.0682 & 0.4229 & 0.9036 \\
6 & 5.3451 & -24.611 & -133.73 & 0.0672 & 0.415 & 0.9073 \\
7 & -3.066 & -3.918 & -96.469 & -0.0093 & -0.0082 & 0.9999 \\
8 & 16.282 & 0.0372 & -109.84 & -0.2472 & 0.4472 & 0.8596 \\
9 & 16.335 & -0.1576 & -110.59 & 0.2466 & 0.4471 & 0.8598 \\
10 & 16.369 & -0.1845 & -111.14 & 0.2463 & 0.4472 & 0.8598 \\
11 & 16.343 & -0.2161 & -110.7 & 0.2463 & 0.4473 & 0.8598 \\
12 & 16.368 & -0.1877 & -111.14 & 0.2463 & 0.4473 & 0.8598 \\
\hline
\end{tabular}

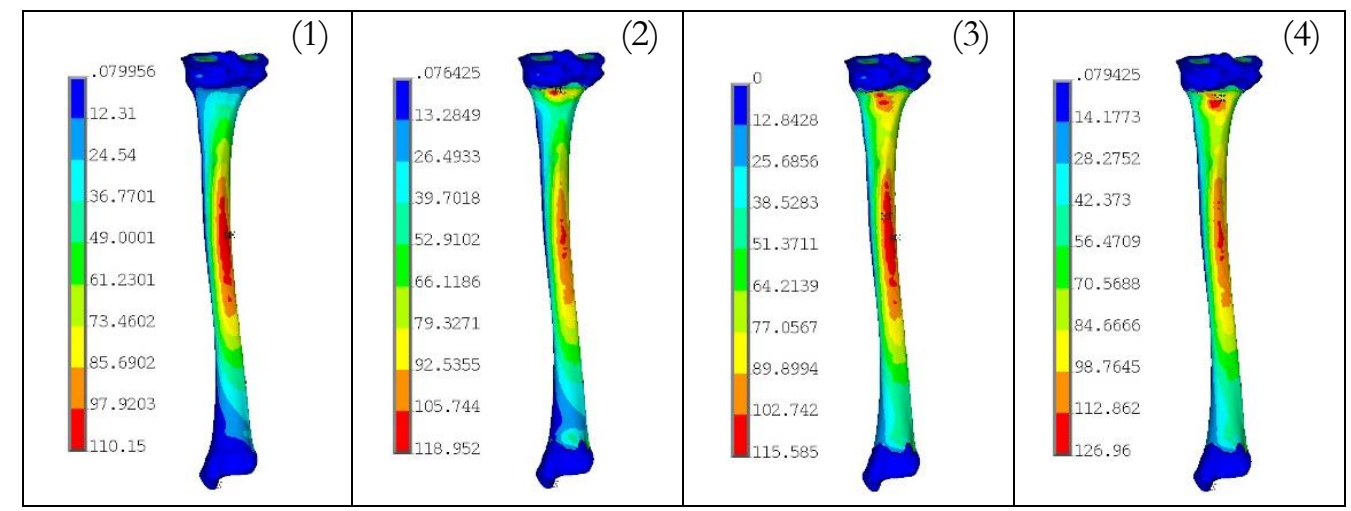




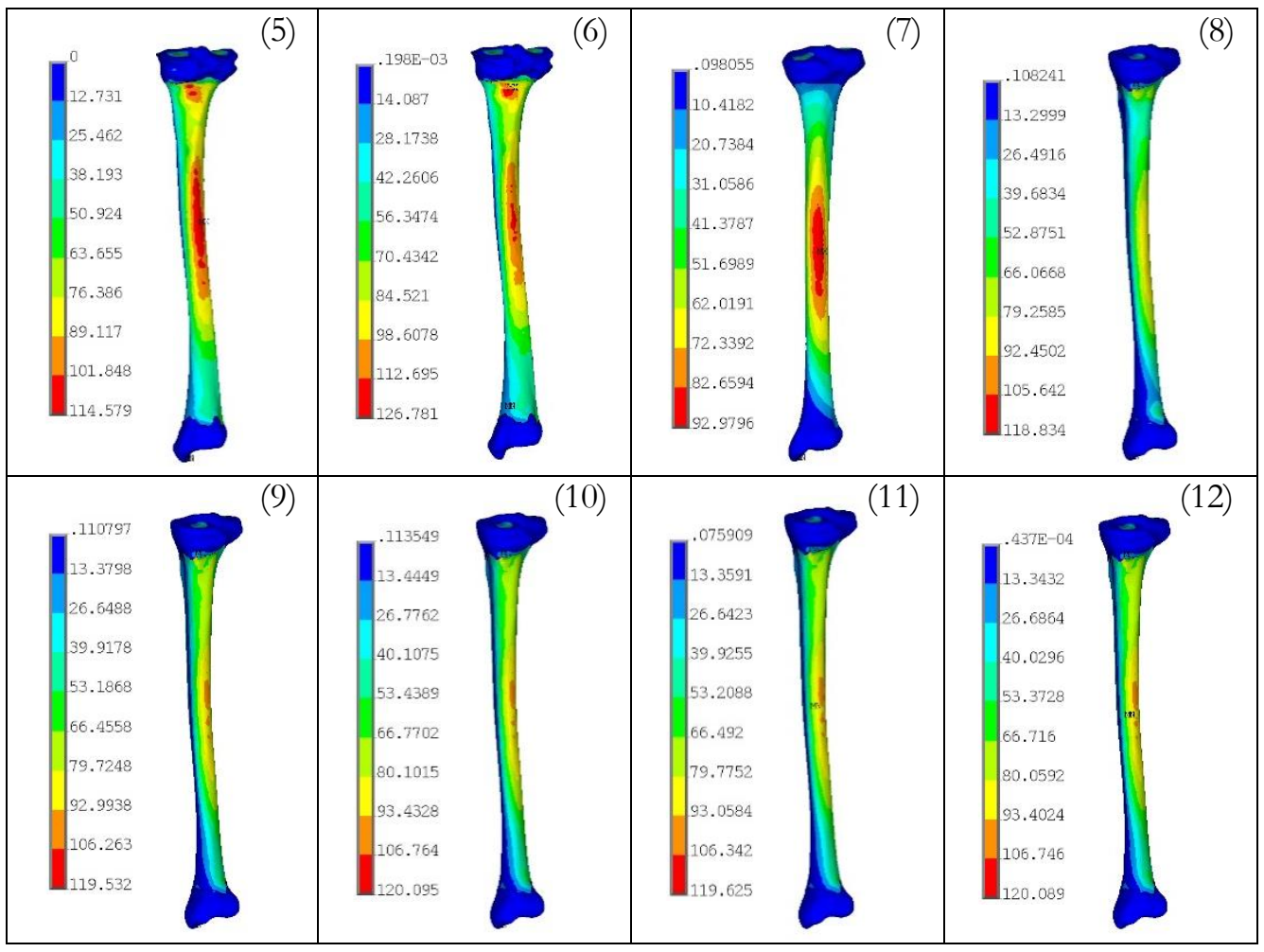

Fig. 12. Von Mises stress distribution (MPa) on tibia surface of female and male for case studies 1-12.

Table 13. Maximum von Mises stresses, Principal stresses and direction cosine of $\sigma_{3}$ at site of maximum von Mises stresses near the middle of the posterior tibia for case studies 13 and 14.

\begin{tabular}{cccccccc}
\hline \multirow{2}{*}{$\begin{array}{c}\text { Case study } \\
\text { number }\end{array}$} & $\begin{array}{c}\text { Maximum von Mises } \\
\text { stresses }\end{array}$ & \multicolumn{3}{c}{ Principal stresses (MPa) } & \multicolumn{3}{c}{ Direction cosine of $\sigma_{3}$} \\
\cline { 3 - 8 } & $(\mathrm{MPa})$ & $\sigma_{1}$ & $\sigma_{2}$ & $\sigma_{3}$ & $\lambda_{1}$ & $\lambda_{2}$ & $\lambda_{3}$ \\
\hline 13 & 120.237 & 0.092 & -1.914 & -121.14 & 0.0329 & 0.0332 & 0.9989 \\
14 & 102.101 & -0.3245 & -1.2789 & -102.9 & -0.0002 & 0.0227 & 0.9997 \\
\hline
\end{tabular}

Table 14. Maximum von Mises stresses, Principal stresses and direction cosine of $\sigma_{3}$ at site of maximum von Mises stresses on the proximal tibia for case studies 13 and 14.

\begin{tabular}{cccccccc}
\hline \multirow{2}{*}{$\begin{array}{c}\text { Case study } \\
\text { number }\end{array}$} & $\begin{array}{c}\text { Maximum von Mises } \\
\text { stresses }\end{array}$ & \multicolumn{3}{c}{ Principal stresses $(\mathrm{MPa})$} & \multicolumn{3}{c}{ Direction cosine of $\sigma_{3}$} \\
\cline { 3 - 8 } & $(\mathrm{MPa})$ & $\sigma_{1}$ & $\sigma_{2}$ & $\sigma_{3}$ & $\lambda_{1}$ & $\lambda_{2}$ & $\lambda_{3}$ \\
\hline 13 & 128.591 & 4.244 & -15.79 & -133.19 & 0.026 & 0.3338 & 0.9423 \\
14 & 117.978 & 12.935 & -0.92 & -111.36 & 0.2382 & 0.4317 & 0.87 \\
\hline
\end{tabular}




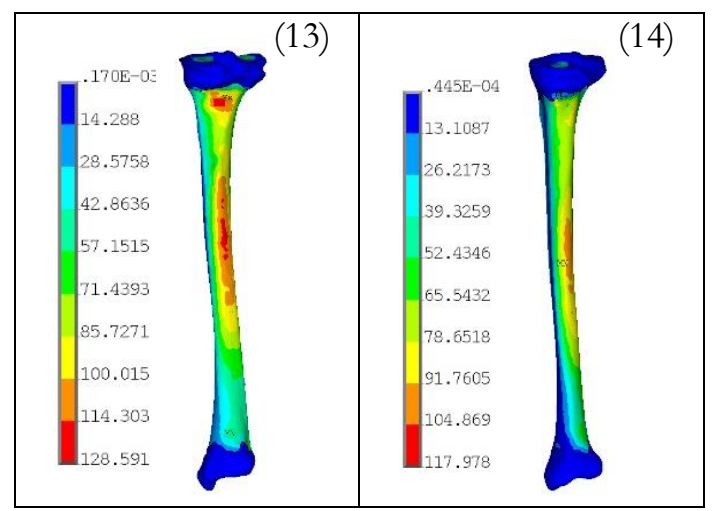

Fig. 13. Von Mises stress distribution (MPa) on tibia surface for case studies 13 and 14.

\section{Conclusion}

The FE models of human tibia bones obtained from CT-images were created and effects of tibia structure and material properties (isotropic and orthotropic materials) on stress distribution in tibia bones during stance phrase running were studied. The 3D tibia models were constructed by using Mimics V.10.01, Geomagic V.10, and Catia V.5 software. The FE models were created in the Hypermesh V.12 software and the ANSYS V.14.5 software was used to analyze the stress distribution in the tibia bones during stance phrase of running.

The benchmark FE models of tibia bones resembling to the real bones were created. We found that there were two sites of maximum von Mises stresses found on tibia bones which were on the middle of posterior tibia and the proximal tibia. However, FE models formed only by cortical bone (case studies 1 and 7) could not capture the peak stresses on the proximal tibia due to the lack of relatively soft subsurface (cancellous bone). The maximum von Mises stresses near the middle of the posterior tibia of FE models with the medullary cavity formed by cortical bone had $6.98 \%$ (female) and $7.05 \%$ (male) higher than ones with the medullary cavity formed by cancellous bone. The bone marrow fat filled in the medullary cavity could not help to support load on the proximal tibia because bone marrow fat has much less Young's modulus than cortical bone. The maximum von Mises stresses of the FE models with the cortical bone formed by orthotropic material had $1.79 \%$ (female) and $2.29 \%$ (male) higher than ones formed by isotropic material properties. The maximum von Mises stress on the proximal tibia obtained from FE models with cortical bone formed by orthotropic material and ones formed by isotropic material had difference less than $1.42 \%$ and $1.77 \%$ for female and male tibia respectively. The main difference of FE models of cortical bone formed by different material properties was directional cosines that predicted the direction of the crack initiation.

\section{Acknowledgement}

The authors acknowledged Phramongkutklao Hospital for the kind provision of CT-images and Department of Industrial Engineering, Kasetsart University for the use of the software.

\section{References}

[1] D. Tarniță, D. Popa, D. N. Tarniță, and D. Grecu, "CAD method for three-dimensional model of the tibia bone and study of stresses using the finite element method," Romanian Journal of Morphology and Embryology, vol. 47, no. 2, pp. 181-186, 2006.

[2] B. Sepehri, A. R. Ashofteh-Yazdi, G. A. Rouhi, and M. Bahari-Kashani, "Analysis of the effect of mechanical properties on stress induced in tibia," in IFMBE Proceedings, 2011, vol. 35, pp. 130-133.

[3] E. Taheri, B. Sepehri, and R. Ganji, "Mechanical validation of perfect tibia 3D model using computed tomography scan," Scientific Research, vol. 4, no. 12, pp. 877-880, 2012.

[4] T. Ruchirabha, T. Puttapitukporn, and S. Sasimontonkul, "Study of stress distribution in the tibia during stance phase running using the finite element method," Kasetsart J. (Nat. Sci.), vol. 48, no. 5, pp. 729-739, 2014. 
[5] P. Aroonjarattham, K. Aroonjarattham, and C. Suvanjumrat, "Effect of mechanical axis on strain distribution after total knee replacement," Kasetsart J. (Nat. Sci.), vol. 48, no. 2, pp. 263-282, 2014.

[6] R. A. Gonzalez-Carbonell, A. Ortiz-Prado, V. H. Jacobo-Armendariz, Y. A. Cisneros-Hidalgo and A. Alp1'zar-Aguirre, "3D patient-specific model of the tibia from CT for orthopedic use," Journal of orthopaedics, vol. 12, no. 1, pp. 11-16, 2015.

[7] R. G. Budynas and K. J. Nisbett, "Load and stress analysis," in Shigley's Mechanical Engineering Design, 8th ed. Singapore: McGraw-Hill, 2008, ch. 3, sec. 9-10, pp. 89-91.

[8] R. Lakes. (2014). Bone: Structure, Physiology, and Mechanics. [Online]. Available: https://ay1415.moodle.wisc.edu/prod/pluginfile.php/69651/mod_resource/content/2/Bone\%2014.ppt

[9] H. Gray, "The tibia," in Anatomy of the Human Body, 20th ed. Philadelphia: Lea \& Febiger, 1918, pp. 1825-1861.

[10] R. O. Rahilly, F. Müller, S. Carpenter, and R. Swenson. (2004). The Bones of the Lower Limb. [Online]. Available: http://www.dartmouth.edu/ humananatomy/part_3/chapter_12.html

[11] J. E. Compston, "Bone marrow and bone: A functional unit," Journal of Endocrinology, vol. 173, no. 3, pp. 387-394, 2002.

[12] R. P. Guillerman, "Marrow: Red, yellow and bad," Pediatr Radiol, vol. 43, no. 1, pp. 181-192, 2013.

[13] D. T. Wang, "Magnetic resonance imaging of bone marrow: A review_Part I," J Am Osteopath Coll Radiol, vol. 1, no. 2, 2012.

[14] M. J. Siegel, "MRI of Bone Marrow," ARRS. St. Louis, MO, USA, 2011.

[15] M. Veselinovic, D. Stevanovic, M. Trajanovic, M. Manic, S. Arsic, M. Trigunovic, and D. Misic, "Method for creating 3D surface model of the human tibia," in 34th International Conference on production engineering, Niš, Serbia, 2011.

[16] J. Y. Rho, "An ultrasonic method for measuring the elastic properties of human tibial cortical and cancellous bone," Ultrasonics, vol. 34, no. 8, pp. 777-783, 1996.

[17] A. Schonninga, B. Oommenb, I. Ionescuc, and T. Conwayd, "Hexahedral mesh development of freeformed geometry: The human femur exemplified," Computer-Aided Design, vol. 41, no. 8, pp. 566-572, 2009.

[18] J. Zhu, H. T. Ma, X. Zhao, R. Ren, and X. Xing, "Finite element analysis of trabecular bone with bone marrow fat," in Proc. TENCON 2013-2013 IEEE Region 10 Conference (31194), IEEE, 2013, pp. 1-4.

[19] L. Wan, R. J. de Asla, H. E. Rubash, and G. Li, "Determination of in-vivo articular cartilage contact areas of human talocrural joint under weight-bearing conditions," Osteoarthritis and Cartilage, vol.14, no. 12, pp. 1294-1301, 2006.

[20] R. V. Eisenhart-Rothea, M. Siebertb, C. Bringmannb, T. Vogl, K. H. Englmeier, and H. Graichen, "A new in vivo technique for determination of 3D kinematics and contact areas of the patello-femoral and tibio-femoral joint," J. Biomech. Eng., vol. 37, no. 6, pp. 927-934, 2003.

[21] S. Sasimontonkul, B. K. Bay, and M. J. Pavol, "Bone contact forces on the distal tibia during the stance phase of running," J. Biomech. Eng, vol. 40, no. 15, pp. 3503-3509, 2007.

[22] National Science and Technology Development Agency. (2004). SizeThailand [Online]. Available http://www.sizethailand.org/region_all.html 